\title{
Effects of microbial inoculation on composting of household organic waste using passive aeration bin
}

\author{
Somjai Karnchanawong • Siriwan Nissaikla
}

Received: 20 November 2013/Accepted: 13 August 2014/Published online: 4 September 2014

(C) The Author(s) 2014. This article is published with open access at Springerlink.com

\begin{abstract}
Background The effects of microbial inoculation with two commercial inoculants and mature compost on the composting of household organic wastes were investigated using five 200-L passive aeration compost bins. Food scraps and dry leaves (1.6 kg total) with a ratio of 1:0.14 (wet weight) were added to each bin once a day, for 60 days, and then further composted for an additional 94 days. The temperature in each bin was recorded daily. Weekly to biweekly, a composite sample of the compost from each bin was analyzed.

Results The $\mathrm{C} / \mathrm{N}$ ratios of composts in the un-seeded and seeded bins stabilized at 81 days and 67-74 days, respectively. The highest volatile solid mass reduction was achieved in the bin seeded with $5 \%$ mature compost.

Conclusions The study revealed that it might not be necessary to add commercial inoculants to facilitate composting of household organic waste. Mature compost can be used as a seed starter to improve composting.
\end{abstract}

Keywords Household organic waste $\cdot$ Passive aeration bin · Inoculation · Mature compost · Commercial inoculants

S. Karnchanawong $(\bowtie) \cdot$ S. Nissaikla Department of Environmental Engineering,

Faculty of Engineering,

Chiang Mai University, Chiang Mai 50200, Thailand

e-mail: somjai@eng.cmu.ac.th

S. Nissaikla

e-mail: campus-koy@hotmail.com

\section{Introduction}

Most municipal solid wastes (MSW) generated in Thailand are disposed of in landfills. Food scraps and garden waste are the major components of organic waste in MSW (OFMSW). The decomposition of OFMSW in landfills produces greenhouse gases. Furthermore, garden waste is usually open-burned in the suburbs and rural areas of Thailand and, as a result, various toxic compounds are released (Kannan et al. 2004). Therefore, organic waste should be separated from MSW and treated properly. Home composting can provide a viable alternative for managing organic waste and the compost produced can be added to the soil to improve its characteristics (Marinari et al. 2000). Bin composting is a suitable treatment option for composting, because it helps the compost pile retain heat and moisture.

The major microbiological components of compost are bacteria and fungi. In addition, actinomycetes, while a particular type of bacteria, are considered as the third major component for their ability to degrade the more recalcitrant compounds. The microorganisms needed for composting are found in compost feedstock, which can maintain an active microbial population during composting. In addition, considerable research has focused on enhancing organic decomposition by inoculating with specific microorganisms. Ohtaki et al. (1998) revealed that inoculations could increase the microbial population, enhance the conversion of organics and reduce odorous gas emissions. Xi et al. (2005) reported that seeding inoculums containing B. azotofixams, B. megaterium, B. mucilaginosus, cellulolytic strains and White-rot fungi was very efficient in accelerating the degradation rate and stabilizing composting products. Vargas-García et al. (2007) determined the influence of microbial inoculation (Bacillus 
shackletonni, Streptomyces thermovulgaris and Ureibacillus thermosphaericus) and co-composting material on the evolution of humic-like substances during composting using the windrow method and concluded that the benefits of inoculation depended on the properties of the applied raw materials and microorganisms. Inoculation with thermo-tolerant lipolytic microbes has been shown to enhance decomposition of food waste and shorten the maturation time in vessel composting (Tsai et al. 2007; Ke et al. 2010).

While many studies have shown that inoculation can enhance composting, most have focused on specific microorganisms and/or large-scale composting systems. Initially, as the microbial population begins to decompose the degradable material in a compost pile, the heat generated is trapped by the compost material, resulting in a temperature rise. If the pile is too large, anaerobic zones occur near the center, slowing decomposition in these zones. If the pile is too small, it loses heat quickly, and also slows down the process. As a result, microorganism activity may vary in different-sized piles. Only two studies have determined the effect of microbial inoculants in small-scale composting. Nair and Okamitsu (2010) used Effective Microorganism (EM) and Trichoderma sp. in composting of putrescible kitchen waste. They combined thermocomposting and vermicomposting and found that ligno-cellulolytic inoculants are not essential to accelerating composting for onsite, small-scale, household organic waste treatment. However, EM inoculation enhanced the reproductive rate of earthworms. Another study was conducted by Abdullah et al. (2013) who determined the effects of using a solution of mixed bacteria of Bacillus sp., Clostridium sp., Pseudomonas sp., Aspergillus sp., Cellulomonas sp., Chaetomium sp., Penicillium sp. and Trichoderma sp. as starter culture on kitchen-waste composting consisting of vegetable scraps and fish processing waste in an in-vessel system. They found that no apparent differences were found in compost with added starter culture.

Studies of small-scale composting using commercial mixed inoculants available on the market are limited. The objective of this research was, therefore, to conduct a performance study of passive-aeration bin composting using three different inoculations with daily batch feeding of household organic wastes.

\section{Materials and methods}

\section{Compost bin and waste loading}

Five 200-L passive aeration bins were prepared with 16 lateral holes $(50 \mathrm{~mm} \times 100 \mathrm{~mm})$ and a vertical pipe connected to an inverted funnel was installed in the middle of the bin (Fig. 1). Food scraps and dry leaves (1.6 kg total) with a ratio of 1:0.14 (wet weight) were added daily to each bin, without mixing, for 60 days. The bins were then allowed to compost for an additional 94 days. This loading pattern was designed to simulate typical household waste generation-estimated from the waste generation of a fourperson household (generation rate of $0.8 \mathrm{~kg} /[\mathrm{cap} \mathrm{d}]$ with $50 \%$ organic portion) (PCD 2007). The food scraps (of which, $50 \%$ was discarded during food preparation and $50 \%$ was leftovers) were collected from a canteen at Faculty of Engineering, Chiang Mai University, Chiang Mai, Thailand. The food preparation scraps were mainly vegetables. The leftover food was primarily rice and noodles, prepared by draining off the liquid portion. All wastes were reduced in size to less than $50 \mathrm{~mm}$. The waste characteristics (avg $\pm \mathrm{SD}, n=9$ ) are shown in Table 1 .

Inoculation details

The inoculants used were mature compost (MC) produced from organic household wastes and two popular inoculants available in the Thai market: EM developed by Dr. Higa and LDD1 produced by the Land Development Department, Thailand. The MC used in this study was obtained from the previous trial of bin composting using food wastes and dry leaves (the same compost mix as in this study) with 3 months of additional curing. The $\mathrm{C} / \mathrm{N}$ ratio and moisture content of MC was 12 and $35 \%$, respectively. EM is a trademarked term commonly used to describe a proprietary blend of three or more types of predominant organisms. EM was first used in Asia in 1989, before moving to other continents. EM is used in many agricultural and environmental management systems including crops, livestock and aquaculture EM is used widely in environmental management for decomposition and, more importantly, for

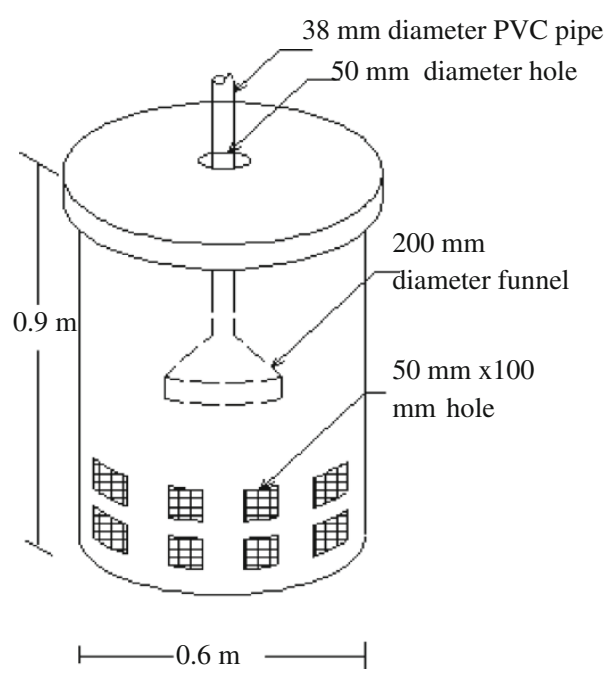

Fig. 1 Diagram showing the composting bins 
Table 1 Characteristics of organic wastes fed in all bins (avg $\pm \mathrm{SD}, n=9$ )

\begin{tabular}{lllllrrr}
\hline Bin & \multicolumn{1}{l}{$\mathrm{pH}$} & $\mathrm{EC}(\mathrm{dS} / \mathrm{m})$ & Moisture content $(\%)$ & $\mathrm{VS}(\%)$ & $\mathrm{C}(\%)$ & $\mathrm{N}(\%)$ & $\mathrm{C} / \mathrm{N}$ ratio \\
\hline 1 & $4.68 \pm 0.46$ & $2.13 \pm 0.16$ & $72.93 \pm 0.85$ & $90.42 \pm 0.58$ & $47.52 \pm 1.63$ & $0.94 \pm 0.07$ & $50.94 \pm 3.55$ \\
2 & $4.60 \pm 0.39$ & $2.16 \pm 0.12$ & $73.23 \pm 0.88$ & $90.48 \pm 0.80$ & $48.13 \pm 1.80$ & $0.95 \pm 0.05$ & $50.79 \pm 3.47$ \\
3 & $4.66 \pm 0.41$ & $2.10 \pm 0.17$ & $73.21 \pm 0.91$ & $90.51 \pm 0.93$ & $48.87 \pm 3.02$ & $0.92 \pm 0.06$ & $53.3 \pm 3.16$ \\
4 & $4.75 \pm 0.46$ & $2.32 \pm 0.24$ & $71.22 \pm 0.83$ & $87.76 \pm 1.38$ & $46.28 \pm 2.16$ & $0.9 \pm 0.08$ & $48.56 \pm 3.25$ \\
5 & $4.92 \pm 0.44$ & $2.50 \pm 0.16$ & $70.18 \pm 1.00$ & $84.3 \pm 1.60$ & $45.33 \pm 1.95$ & $1.00 \pm 0.06$ & $45.36 \pm 2.07$ \\
\hline
\end{tabular}

Table 2 Characteristics and amount of inoculants seeded in the composting process

\begin{tabular}{lllllll}
\hline Bin & Inoculant & $\mathrm{pH}$ & \multicolumn{2}{c}{ cfu/g or cfu/mL } & $\begin{array}{l}\text { Amount seeded in each bin, } \\
\mathrm{nnnyyy}\end{array}$ \\
\cline { 3 - 6 } & & Bacteria & Fungi & Actinomycetes & \\
\hline 1 & Control bin & & & & \\
2 & EM & 3.31 & $3.77 \times 10^{2}$ & $3.31 \times 10^{2}$ & $3.37 \times 10^{2}$ & $16 \mathrm{~mL}$ \\
3 & LDD1 & 6.10 & $1.37 \times 10^{4}$ & $7.96 \times 10^{2}$ & $8.13 \times 10^{2}$ & $0.16 \mathrm{~g}$ \\
4 & MC $(2 \%)$ & 7.46 & $7.82 \times 10^{3}$ & $5.01 \times 10^{2}$ & $5.64 \times 10^{2}$ & $32 \mathrm{~g}$ \\
5 & MC $(5 \%)$ & 7.46 & $7.82 \times 10^{3}$ & $5.01 \times 10^{2}$ & $5.64 \times 10^{2}$ & $80 \mathrm{~g}$ \\
\hline
\end{tabular}

recycling of both solid and liquid wastes (Higa 1991; Higa and Wididana 1991); it is reported to include lactic acid bacteria, photosynthetic bacteria and yeast (Szymanski and Patterson 2003). EM used in this study was bought from EM Q-Sei Company. LDD1, produced by the Land Development Department, Thailand, consists of fungi, actinomycetes and lipase-producing bacteria; it is widely distributed and is used to compost organic waste in Thailand.

In this study, five bins were prepared for the experiment. Bin 1, a control bin, was not inoculated. bins 2-5 were inoculated using EM, LDD1, 2 and $5 \%$ MC, respectively. EM and LDD1 were mixed with the organic waste daily, as specified by the developers (Table 2). EM is highly acidic, LDD1 slightly acidic and MC slightly basic. LDD1 inoculants contained the most microbes, followed by the 5, $2 \%$ $\mathrm{MC}$ and EM inoculants.

\section{Sample analysis}

During the waste-loading period, the fresh organic waste fed into the bin was sampled and analyzed weekly. Biweekly compost samples were randomly taken from the middle portion of the bins to determine $\mathrm{pH}$, electrical conductivity (EC) and microbial counts. After the waste-loading period, weekly to biweekly compost samples were randomly taken from the middle portion of the bins to analyze $\mathrm{pH}, \mathrm{EC}$, moisture content, $\mathrm{C}$, N, volatile solids (VS) and microbial counts. The temperature in the middle of the waste layer was measured daily. At the end of the composting period, the compost was weighed and piled for another 30 days to allow the compost to mature. Finally, the composts were analyzed for $\mathrm{pH}, \mathrm{EC}$, moisture content, C, cationexchange capacity (CEC), germination index (GI), and $\mathrm{N}, \mathrm{P}$ and $\mathrm{K}$ values. All analyses for each sample were conducted in triplicate.

Temperatures were recorded using a glass thermometer. The $\mathrm{pH}$ and EC were determined by measuring slurry of a 1:10 ratio of compost to water using a Horiba F-21 pH meter and a WTW 330i conductivity meter, respectively. Carbon and nitrogen contents were determined using methods based on Walkley and Black (1934) and a modified micro Kjeldahl procedure (AOAC 1980), respectively. VS were determined using a gravimetric method (APHA 1997) and CEC was measured using a displacement method and distillation for the adsorbed ammonium (Schollenberger and Dreibelbis 1930). Phosphorus was analyzed using $\mathrm{HNO}_{3}-\mathrm{HClO}_{4}$ digestions, followed by a colorimetric method using Barton's solution, and potassium was determined using $\mathrm{HNO}_{3}-\mathrm{HClO}_{4}$ digestions and a flame photometer (AOAC 2000). Seed germination was carried out using flowering white cabbage seeds (Brassica chinensis var. parachinensis) based on the method described by Zucconi et al. (1981). The dilution plate method (AOAC 2000) was used to enumerate bacteria, fungi and actinomycetes using nutrient agar, potato dextrose agar and yeast extract-malt extract agar, respectively. The plates were incubated at $35^{\circ} \mathrm{C}$. Bacterial counts were recorded 2 days after plating. Fungal and actinomycetic counts were recorded 5 days after plating.

Statistical analysis

One-way ANOVA at a $95 \%$ confidence limit was conducted to compare the study results. 
Fig. 2 Temperature variations in the compost bins

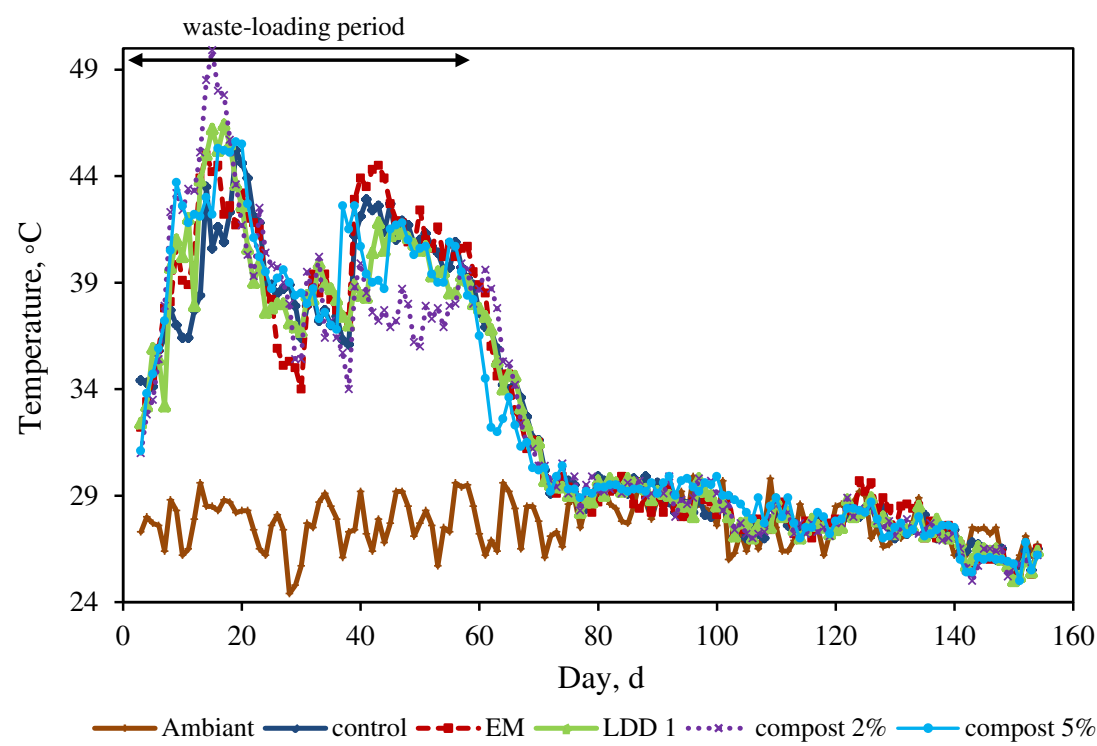

\section{Results and discussion}

Compost characteristics variation

All five bins showed similar changes in temperature (Fig. 2). The temperature in each bin reached a maximum during the 2nd and 3rd weeks of the waste-loading period. Following this, the temperature generally reduced, before increasing again at weeks 6 and 7. The second temperature peak occurred after the waste level in each bin exceeded the level of the inverted funnel (Fig. 1). This might have resulted in a passive aeration effect, causing the higher biodegradation activity. The highest temperatures during the waste-loading period were observed in Bin $4\left(49.9^{\circ} \mathrm{C}\right)$, followed by bins 3, 5, 1 and 2 (46.4, 45.6, 45.2 and $45.0^{\circ} \mathrm{C}$, respectively). The mean temperatures observed in all bins during the waste-loading period ranged from 39.5 to 40.0 and 28.6 to $28.7^{\circ} \mathrm{C}$, but were not significantly different from each other $(p>0.05)$. After the wasteloading period, the temperatures continued to decrease towards the ambient temperature and no significant difference was also observed among all bins. Normally, compost should be kept in the thermophilic range for 2 weeks to inactivate or kill pathogens. However, in this study, the thermophilic phase took place over only a few days in all of the bins, due to the heat loss from the high surface-volume ratio of the smaller volume bins. These results corresponded to the studies of Nair et al. (2006), Nair and Okamitsu (2010) and Colóna et al. (2010). Therefore, the compost hygienization may not be assured. However, according to the study of Colóna et al. (2010) who determine the environmental burdens of home composting using bin, they found that the final compost produced in bin was hygienized since Salmonella was not detected and less than $10 \mathrm{CFU} / \mathrm{g}$ of $E$. coli were found.

The compost characteristic variations are presented in Fig. 3. The $\mathrm{pH}$ and $\mathrm{EC}$ of the waste in the bins started from 4.87 to 5.33 and 2.03 to $2.37 \mathrm{dS} / \mathrm{m}$, respectively (Fig. 3). After waste-loading period, bins 1-3 had significantly lower $\mathrm{pH}$ values, compared with bins 4 and $5(p<0.05)$, due to the higher $\mathrm{pH}$ of the added MC. The $\mathrm{pH}$ of the compost in all bins increased to 7.2-8.0. The increase in $\mathrm{pH}$ may be explained by the release of ammonia following the degradation of organic compounds, such as protein and amino acids (Cáceres et al. 2006). At the end of the composting period, the EC values increased to a range of 2.68-3.80 dS/m, which could be attributed to the release of mineral salts and ammonium ions through the decomposition of organic matter. After waste-loading period, bins 4 and 5 had significantly higher EC values than bins 1-3 $(p<0.05)$ due to the higher inorganic content in the mature composts added.

The $\mathrm{C} / \mathrm{N}$ ratio of fresh organic wastes ranged from 45.4 to 53.3 , before continuously decreasing and finally stabilizing at 14.6, 13.0, 13.8, 12.4 and 10.5, for bins 1-5, respectively. After waste-loading period, bins 4 and 5 had a significantly lower $\mathrm{C} / \mathrm{N}$ ratio than all other bins $(p<0.05)$. The $\mathrm{C} / \mathrm{N}$ ratios of the composts in all Bins fell below 15 , indicating that the maturity of the compost was achieved (Golueke 1981).

The organic waste used in this study contained high VS, reflecting the high proportion of biodegradable matter. The VS decreased from a range of 80.9-90.0\% at the beginning of the composting period, to a range of 57.4-80.7 \% at the end. The majority of VS reduction occurred during the first 2 months after the waste-loading period. The lower 
Fig. 3 Variations in compost characteristics
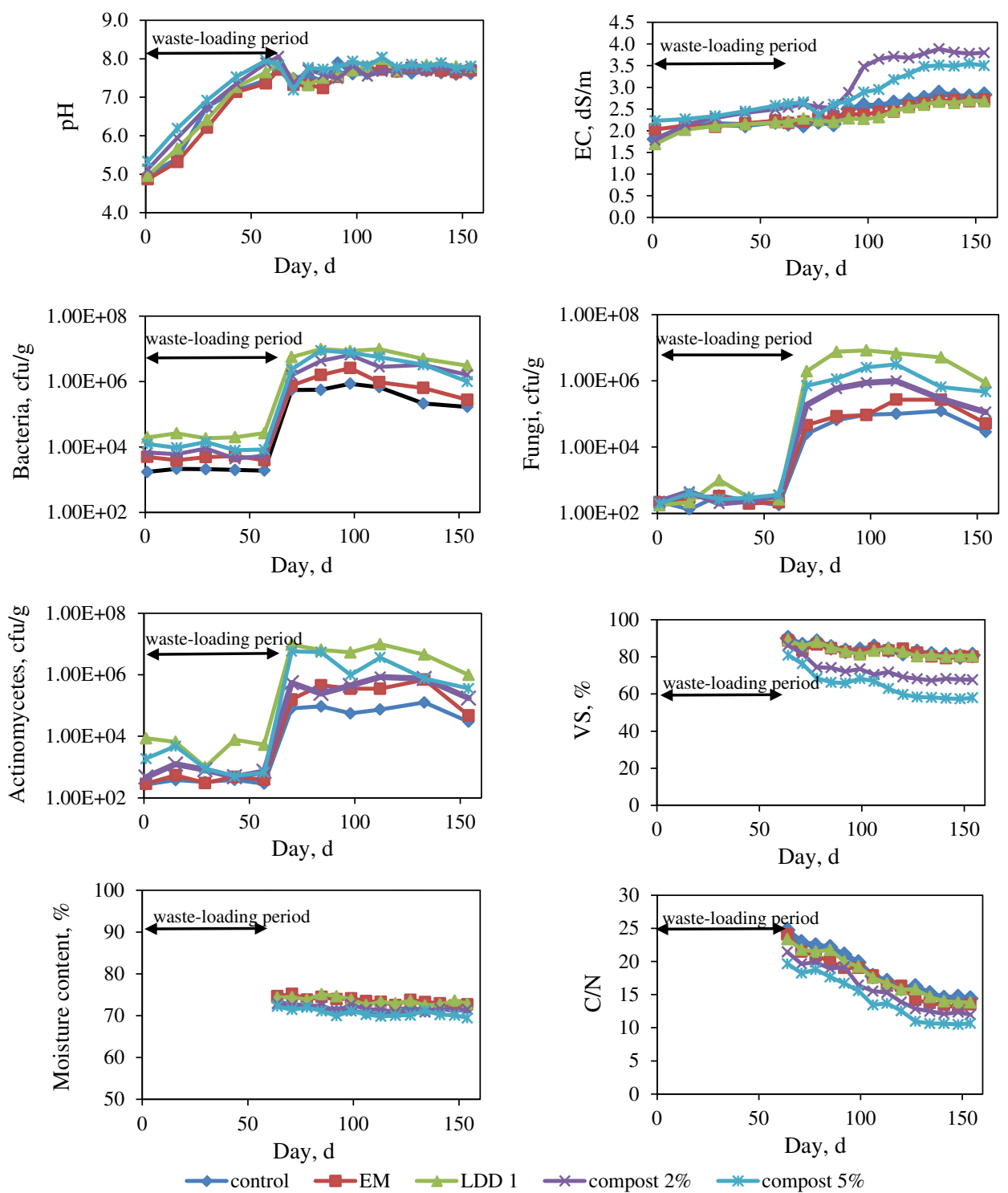

significant values of VS were found between bins 4 and 5 , and between the group of bins 4 and 5 with the group of bins $1-3$.

During the waste-loading period, the bacteria dominated, compared with the fungi and actinomycetes. After the waste-loading period, all microbial contents sharply increased 100- to 1,000-fold. This increase might be because the growth of microorganisms in the mesophilic range, occurring after the waste-loading period, was greater than in the thermophilic range, occurring during the wasteloading period. In addition, the microbial plates were inoculated at $35^{\circ} \mathrm{C}$, so the thermophilic microorganisms were grown on the plates, resulting in the lower number of microorganisms obtained in this study. However, the microbial succession was in agreement with Ryckeber et al.
(2003), who showed that fungi and actinomycetes proliferated when the temperature was low and that thermophilic bacteria dominated when it was high. Bin 3 showed the highest counts of all three microbial contents, both during and after the waste-loading period, followed by bins 5, 4, 2 and 1 , respectively. bins 3 and 5 had significantly higher microbial counts, compared to all other bins $(p<0.05)$.

The composting time and finished compost characteristics

The composting times to stabilize the $\mathrm{C} / \mathrm{N}$ ratio and $\mathrm{VS}$ of the compost materials in bins 1-5 were 81, 74, 74, 67 and 67 days after the waste-loading period, respectively, for the $\mathrm{C} / \mathrm{N}$ ratio; and 88, 74, 67, 74 and 67 days after the waste- 
Table 3 Finished compost characteristics

Table 4 Total mass and volatile solid mass reductions

\begin{tabular}{llllllll}
\hline Bin & $\mathrm{pH}$ & $\begin{array}{l}\mathrm{EC}(\mathrm{dS} / \\
\mathrm{m})\end{array}$ & $\begin{array}{l}\text { Moisture content } \\
(\%)\end{array}$ & $\mathrm{C} / \mathrm{N}$ & $\begin{array}{l}\mathrm{GI} \\
(\%)\end{array}$ & $\begin{array}{l}\mathrm{CEC}(\mathrm{cmol} / \\
\mathrm{kg})\end{array}$ & $\begin{array}{l}\mathrm{N}-\mathrm{P}-\mathrm{K}\left(\% \mathrm{~N}, \% \mathrm{P}_{2} \mathrm{O}_{5},\right. \\
\left.\% \mathrm{~K}_{2} \mathrm{O}\right)\end{array}$ \\
\hline 1 & 7.7 & 4.5 & 61.7 & 13.4 & 139.1 & 71.5 & $2.52-0.87-2.26$ \\
2 & 7.8 & 4.2 & 63.1 & 11.5 & 146.6 & 71.6 & $2.85-0.90-2.83$ \\
3 & 7.9 & 4.4 & 62.1 & 12.7 & 152.9 & 72.7 & $2.58-0.83-2.08$ \\
4 & 7.9 & 5.0 & 61.5 & 11.5 & 155.5 & 71.6 & $2.60-0.86-2.47$ \\
5 & 7.8 & 4.6 & 59.9 & 10.7 & 158.7 & 72.2 & $2.75-0.72-2.35$ \\
\hline
\end{tabular}

\begin{tabular}{|c|c|c|c|c|c|c|}
\hline \multirow[t]{2}{*}{ Bin } & \multicolumn{2}{|c|}{ Dry mass $(\mathrm{kg})$} & \multirow{2}{*}{ Reduction $(\%)$} & \multicolumn{2}{|c|}{ Dry VS mass $(\mathrm{kg})$} & \multirow{2}{*}{ Reduction $(\%)$} \\
\hline & Beginning & End & & Beginning & End & \\
\hline \multicolumn{7}{|c|}{ Including of MC mass in Bin 4 and 5} \\
\hline 1 & 26.03 & 7.23 & 72.22 & 23.54 & 5.85 & 75.2 \\
\hline 2 & 25.74 & 6.88 & 73.27 & 23.29 & 5.51 & 76.3 \\
\hline 3 & 25.76 & 6.92 & 73.14 & 23.31 & 5.57 & 76.1 \\
\hline 4 & 28.22 & 8.70 & 69.17 & 24.76 & 5.88 & 76.3 \\
\hline 5 & 30.10 & 11.03 & 63.36 & 25.38 & 6.39 & 74.8 \\
\hline \multicolumn{7}{|c|}{ Excluding of MC Mass in Bin 4 and 5} \\
\hline 1 & 26.03 & 7.23 & 71.2 & 23.54 & 5.85 & 75.2 \\
\hline 2 & 25.74 & 6.88 & 72.4 & 23.29 & 5.51 & 76.3 \\
\hline 3 & 25.76 & 6.92 & 72.2 & 23.31 & 5.57 & 76.1 \\
\hline 4 & 26.74 & 7.22 & 72.1 & 24.13 & 5.25 & 78.2 \\
\hline 5 & 26.42 & 7.35 & 71.2 & 23.81 & 4.82 & 80.0 \\
\hline
\end{tabular}

loading period, respectively, for VS. Therefore, microbial inoculation enhanced biological activities during composting, and shortened the stabilization period by 1-2 weeks.

The finished composts characteristics are presented in Table 3. The $\mathrm{pH}$ and conductivities of the finished composts from all bins ranged from 7.0 to 8.0 and 4.2 to $4.5 \mathrm{dS} /$ $\mathrm{m}$, respectively. The moisture contents ranged from 59.9 to $63.2 \%$, all $\mathrm{C} / \mathrm{N}$ ratios were $<15$ and all GIs were $>140$, showing that the composts were mature and not phytotoxic (Zucconi et al. 1981). All the composts had similar levels of CEC and N:P:K. The bins seeded with MC showed the lowest $\mathrm{C} / \mathrm{N}$ ratio and the highest $\mathrm{GI}$, even though the Bin seeded with LDD1 contained the highest numbers of microorganisms. This might be because the microorganisms in the MC were adapted to the environment of the household organic wastes composting, compared with the LDD1.

The total mass and volatile solid mass reductions in all bins during the composting period exceeded 63 and $74 \%$, respectively (Table 4). The total mass reduction of bins 2 and 3 was not different from the control Bin, while the total mass reduction of bins 4 and 5 was less than the control Bin. This could be because the MC amounts added during the waste-loading period in bins 4 and 5 were larger than the EM and LDD1 amounts added to bins 2 and 3. The MC was already in a stabilized state and low in readily available carbon compounds, therefore, its total mass reduction during the composting period can be assumed to be negligible. When the mass of MC was deducted, the percentage reduction in the total mass of all bins was similar (Table 4). However, the VS mass reductions in the bins seeded by $\mathrm{MC}$ were slightly greater than the bins seeded by EM and LDD1 and the control Bin.

This study has shown that adding EM and LDD1 to facilitate composting may not be necessary. This conclusion corresponds with Nair and Okamitsu (2010) and Abdullah et al. (2013) who concluded that the starter culture is not essential to accelerating the composting of kitchen waste. When comparing the results obtained from bins 4 and 5 and the control Bin, MC in both bins accelerated composting by approximately 2 weeks. The finished compost produced from these bins had a lower $\mathrm{C} / \mathrm{N}$ ratio, higher GI, higher fraction of compost smaller than $12.5 \mathrm{~mm}$ and higher volatile mass reduction. Bin 5 (5\% MC) produced compost with better final characteristics than Bin 4 (2\% MC). Therefore, inoculation with MC was effective in composting household organic wastes, even though the improvement was not very high. 


\section{Conclusions}

The study composted household organic wastes, inoculated with two popular, commercially available inoculants in Thailand and mature compost. The study revealed that it might not be necessary to add commercial inoculants to facilitate composting of household organic waste due to the slight improvement of the finished compost. The mature compost can be used as a seed starter to improve composting, producing a finished compost with better characteristics.

Conflict of interests The authors declare that they do not have any competing interests.

Open Access This article is distributed under the terms of the Creative Commons Attribution License which permits any use, distribution, and reproduction in any medium, provided the original author(s) and the source are credited.

\section{References}

Abdullah N, Chin NL, Mokhtar MN, Taip FS (2013) Effects of bulking agents, load size or starter cultures in kitchen-waste composting. Int J Recycl Org Waste Agric 2:3. doi:10.1186/ 2251-7715-2-3

AOAC (1980) Official methods of analysis, 13th ed. Association of Official Analytical

AOAC (2000) Official methods of analysis. Association of Official Analytical Chemist. EUA

APHA (1997) Standard methods for the examination of water and wastewater. American Public Health Association, Washington, $\mathrm{DC}$

Cáceres R, Flotats X, Marfà O (2006) Changes in the chemical and physicochemical properties of the solid fraction of cattle slurry during composting using different aeration strategies. Waste Manag 26:1081-1091

Colóna J, Martínez-Blancoc J, Gabarrella X, Artolaa A, Sáncheza A, Rieradevalla J, Fonta X (2010) Environmental assessment of home composting. Resour Conserv Recycl 54:893-904

Golueke CG (1981) Principles of biological resource recovery. BioCycle 22:36-40

Higa T (1991) Effective microorganisms: a biotechnology for mankind. In: Parr JF, Hornick SB, Whitman CE (eds) Proceedings of the first international conference on kyusei nature farming. US Department of Agriculture, Washington, DC

Higa T, Wididana GN (1991) The concept and theories of effective microorganisms. In: Parr JF, Hornick SB, Whitman CE (eds)
Proceedings of the 1 st international conference on kyusei nature farming. US Department of Agriculture, Washington, DC, pp 118-124

Kannan GK, Gupta M, Kapoor JC (2004) Estimation of gaseous products and particulate matter emission from garden biomass combustion in a simulation fire test chamber. Atmos Environ 38:6701-6710

Ke GR, Lai CM, Liu YY, Yang SH (2010) Inoculation of food waste with the thermo-tolerant lipolytic actinomycete Thermoactinomyces vulgaris $\mathrm{A} 31$ and maturity evaluation of the compost. Bioresour Technol 101:7424-7431

Marinari S, Masciandaro G, Ceccanti B, Grego S (2000) Influence of organic and mineral fertilisers on soil biological and physical properties. Bioresour Technol 72:9-17

Nair J, Okamitsu K (2010) Microbial inoculants for small scale composting of putrescible kitchen wastes. Waste Manag 30:977-982

Nair J, Sekiozoic V, Anda M (2006) Effect of pre-composting on vermicomposting of kitchen waste. Bioresour Technol 97:2091-2095

Ohtaki A, Akakura N, Nakasaki K (1998) Effects of temperature and inoculums on the degradability of poly- $\varepsilon$-caprolactone during composting. Polym Degrad Stab 62:279-284

PCD (2007) Municipal waste reduction and recycling in Thailand. http://infofile.pcd.go.th/waste/waste_volumn.xls. Accessed 7 October 2010

Ryckeber J, Mergaert J, Coosemans J, Deprins K, Swings J (2003) Microbiological aspects of biowaste during composting in a monitored compost bin. J Appl Microbiol 94:127-137

Schollenberger CJ, Dreibelbis FR (1930) Analytical methods in base exchange investigations on soils. Soil Sci 30:161-173

Szymanski N, Patterson RA (2003) Effective microorganisms (EM) and wastewater systems in future directions for on-site systems: best management practice. In: Patterson RA, Jones MJ (eds) Onsite'03 Conference. Lanfax Laboratories, Armidale

Tsai SH, Liu CP, Yang SS (2007) Microbial conversion of food wastes for biofertilizer production with thermophilic lipolytic microbes. Renew Energ 32:904-915

Vargas-García MC, Suárez-Estrella F, López MJ, Moreno J (2007) Effect of inoculation in composting processes: modifications in lignocellulosic fraction. Waste Manag 27:1099-1107

Walkley A, Black IA (1934) An examination of the Degtjareff method for determining organic carbon in soils: effect of variations in digestion conditions and of inorganic soil constituents. Soil Sci 63:251-263

Xi B, Zhang G, Liu H (2005) Process kinetics of inoculation composting of municipal solid waste. J Hazard Mater 124:165-172

Zucconi F, Forte M, Monaco A (1981) Biological evaluation of compost maturity. BioCycle 22:27-29 